\title{
Trends of Hyperuricemia Prevalence among the Urban and Rural Chinese Populations of the Southeast Coastal Region During the Years 2014- 2018: A Retrospective Study
}

\section{Xu-xin Zhu}

the First Affiliated Hospital of Shantou University Medical College

Min-hua Hu

the First Affiliated Hospital of Shantou University Medical College

Pei-xuan Yang

Shantou University Medical College

Chun-na Wu

Shantou Chaonan Minsheng Hospital, Shantou, Guangdong 515144, P. R. China

Yong-song Chen ( $\sim$ yongsongchen@126.com )

the First Affiliated Hospital of Shantou University Medical College

Li-ping Li

Shantou University Medical College

\section{Research Article}

Keywords: Serumuricacid, Hyperuricemia, Prevalence, Trends

Posted Date: March 15th, 2021

DOl: https://doi.org/10.21203/rs.3.rs-288757/v1

License: (c) This work is licensed under a Creative Commons Attribution 4.0 International License.

Read Full License 
1 Trends of hyperuricemia prevalence among the urban and rural

2 Chinese populations of the southeast coastal region during the years

3 2014-2018: A retrospective study

4 Xu-xin $\mathrm{Zhu}^{1,2,5}$, Min-hua $\mathrm{Hu}^{1,2}$, Pei-xuan Yang ${ }^{2,3}$, Chun-na $\mathrm{Wu}^{4}$,

$5 \quad$ Yong-song Chen ${ }^{1,2^{*}}$ and Li-ping $\mathrm{Li}^{5^{*}}$

6

7 Xu-xin Zhu (57 Changping Road, Jinping District, Shantou, Guangdong $8 \quad$ 515041, P.R. China)

9 Min-hua Hu (57 Changping Road, Jinping District, Shantou, Guangdong $10 \quad$ 515041, P.R. China)

11 Pei-xuan Yang (57 Changping Road, Jinping District, Shantou, 12 Guangdong 515041, P.R. China)

13 Chun-na Wu (324 National Highway, Chaonan District, Shantou, 14 Guangdong 515144, P.R. China)

16 Corresponding authors:

$17 \quad$ Li-ping Li

1822 Xinling Road, Jinping District, Shantou, Guangdong 515041, P.R.

19 China

20 Phone: 13825883963

21 E-mail: lpli@stu.edu.cn

$22 \&$ 
2457 Changping Road, Jinping District, Shantou, Guangdong 515041, P.R.

25 China

26 Phone: +86-0754-88905385

27

E-mail: yongsongchen@126.com

28

29

30

31

32

33

34

35

36

37

38

39

40

41

42

43

44 


\footnotetext{
*Correspondence:yongsongchen@126.com;lpli@stu.edu.cn

${ }^{1}$ Department of Endocrinology and Metabolism, the First Affiliated Hospital of Shantou University Medical College, Shantou, Guangdong 515041, P. R. China

${ }^{2}$ The Clinical Research Center, the First Affiliated Hospital Shantou University Medical College, Shantou, Guangdong 515041, P. R. China

${ }^{5}$ Department of Prevention Center of Injury, Shantou University, Shantou, Guangdong 515041, P. R. China

Full list of author information is available at the end of the article
} 
respectively, $P<0.01)$ and higher in men than women $(437.87 \pm 93.98$ $\mu \mathrm{mol} / \mathrm{L}$ vs $338.21 \pm 83.43 \mu \mathrm{mol} / \mathrm{L}$ and $54.78 \%$ vs $15.00 \%$, respectively, $P<0.01)$. Both SUA levels $(P<0.01)$ and HUA prevalence $(P<0.01)$ increased with advancing age in urban areas, while seemingly decreasing and remaining stable after the age of 50 years in rural areas. Although both SUA levels $(P<0.001)$ and HUA prevalence $(P<0.001)$ showed a downward trend in men and an upward trend in women after age 40 in both areas, men had greater disease burden than women.

Conclusions: This is the first investigation of SUA levels and HUA prevalence trends among the urban and rural Chinese population of the southeast coastal region. Increases in both SUA levels and HUA prevalence were observed in both areas during 2014-2018. Although there was a downward trend in men and an upward trend in women of the SUA levels and the HUA prevalence, men had higher disease burden. Attention should be paid and effective measures should be taken to lower the HUA prevalence for men in this population.

Keywords: Serum uric acid, Hyperuricemia, Prevalence, Trends 


\section{Background}

Serum uric acid (SUA) is the end product of purine metabolism. Hyperuricemia (HUA) is a condition characterized by abnormally elevated SUA levels that results from excessive SUA production and/or decreased SUA excretion. Elevated SUA concentration leads to gout and impairs patients' quality of life and wellbeing. Moreover, accumulating evidence has demonstrated that HUA is associated with hypertension ${ }^{1}$, cardiovascular disease $^{2,3}$, stroke $^{4}$, diabetes ${ }^{5,6}$, and metabolic syndrome ${ }^{7}$. Epidemiological investigations found an increasing trend of HUA prevalence in Western countries ${ }^{8-10}$. However, there was a decreasing trend observed in Japan and Taiwan ${ }^{11,12}$. Studies investigating the trends of HUA prevalence among the Chinese population of the southeast coastal region remain scarce. Hence, the present study aimed to assess the trends of SUA levels and the prevalence of HUA in this population.

\section{Methods}

\section{Data source}

Data were extracted from the health care centers of the First Affiliated Hospital of Shantou University Medical College, which is located in the urban area of Shantou City, Guangdong Province, China, and Shantou Chaonan Minsheng Hospital, which is located in the rural area of Shantou City. 
Subjects who participated in routine checkups in 2014-2018 and had

110 complete body measurements and laboratory parameters were

111 investigated in our study. Subjects with missing data for age, gender,

112 height, body weight and SUA levels were excluded. The study protocol

113 was approved by the Research Ethics Committees of the First Affiliated

114 Hospital of Shantou University Medical College and Shantou Chaonan

115 Minsheng Hospital. Written informed consent was obtained from all

116 subjects or from a parent in subjects under 18 before data extraction. All

117 procedures were performed in accordance with Chinese guideline

118 Measures for the Ethical Review of Biomedical Research Involving

119 Human Beings on the use of medical data for research.

\section{Data extraction}

121 Two reviewers extracted the information on age, gender, height, body

122 weight, and SUA levels from the subjects. Any disagreement on data

123 extraction between the two reviewers was mediated by discussion.

124

125

126

127

128

129

\section{Definition}

HUA was defined as an SUA concentration of more than $420 \mu \mathrm{mol} / \mathrm{L}$ (7 $\mathrm{mg} / \mathrm{dL})^{13}$.

\section{Statistical analyses}

SPSS 22.0 was used for data processing and statistical analyses. Data were entered twice by two different reviewers. The distribution of SUA 
136 statistically significant.

\section{Results}

145 had higher levels of SUA and HUA prevalence than women and subjects

146 from rural areas, respectively $(P<0.01)$.

147 Table 1 Mean SUA level and HUA prevalence in 2014-2018

\begin{tabular}{llcccc}
\hline & \multicolumn{1}{c}{ Total } & Male & Female & Urban & Rural \\
\hline Mean SUA level & $395.49 \pm 102.29$ & $437.87 \pm 93.98$ & $338.21 \pm 83.43^{\mathrm{a}^{*}}$ & $397.59 \pm 103.01$ & $388.03 \pm 99.34^{\mathrm{b}^{*}}$ \\
$\mathrm{M} \pm \mathrm{SD}(\mu \mathrm{mol} / \mathrm{L})$ & & & & & \\
HUA prevalence & 37.87 & 54.78 & $15.00^{\mathrm{a}^{*}}$ & 38.70 & $34.89^{\mathrm{b}^{*}}$ \\
\hline
\end{tabular}


$148 \quad \mathrm{a}^{*}$ :compared with male, $P<0.01$.

$149 \mathrm{~b}^{*}:$ compared with urban, $P<0.01$.

$150 \quad \mathrm{M}$ mean and SD standard deviation.

151 During the observation period, there was an increase in the SUA levels 152 from $382.54 \pm 91.17 \mu \mathrm{mol} / \mathrm{L}$ in 2014 to $407.38 \pm 103.97 \mu \mathrm{mol} / \mathrm{L}$ in 2018 in 153 urban areas and from $367.75 \pm 90.76 \mu \mathrm{mol} / \mathrm{L}$ to $398.42 \pm 104.61 \mu \mathrm{mol} / \mathrm{L}$ in 154 rural areas (Figure 1). There was also an increase in the prevalence of 155 HUA from $32.87 \%$ to $42.41 \%$ in urban areas and from $27.81 \%$ to $38.81 \%$ 156 in rural areas during the same period (trend for $P<0.01$ ) (Figure 2).

\section{Trends in SUA levels and prevalence of hyperuricemia by age}

The overall SUA level $(P<0.01)$ and HUA prevalence $(P<0.01)$ increased with age in urban areas, with the highest level $(410.75 \pm 99.87 \mu \mathrm{mol} / \mathrm{L})$ and highest prevalence (43.04\%) among subjects aged 70 years or older (Figure 3). However, the overall SUA level and HUA prevalence peaked in the 30-39 age group and appeared to decrease and remain stable after the age of 50 years in rural areas (Figure 4 ).

\section{Trends in SUA levels and prevalence of hyperuricemia by gender}

During the 5-year period, both the SUA levels and HUA prevalence stayed relatively stable under the age of 40 years for both sexes in urban and rural areas. After the age of 40 years, SUA levels and HUA prevalence appeared to decrease for men in both areas (Figure 5). Women, 
however, continued to show an upward trend with age (trend for $P<0.001$ ) (Figure 6).

\section{Discussion}

The current study showed that the mean SUA levels and HUA prevalence were $395.49 \pm 102.2 \mu \mathrm{mol} / \mathrm{L}$ and $37.87 \%$, respectively. A recent meta-analysis evaluated the HUA prevalence in the general Chinese population from 2000 to 2014 and reported that the HUA prevalence was $13.3 \%{ }^{14}$. The HUA prevalence in the population of the southeast coastal region of China in the present study was remarkably higher than in the general Chinese population. Xie et al ${ }^{15}$ investigated the HUA prevalence in the Chinese population of the southeast coastal region in 2011 and showed that the HUA prevalence was $37.1 \%$. Compared with 2011, the HUA prevalence showed a tendency to increase among this population in 2014-2018. Furthermore, substantial increasing trends in both SUA levels and HUA prevalence were observed in both urban and rural Chinese populations of the southeast coastal region in 2014-2018 and may still be increasing. Our findings are consistent with previous investigations that observed an increasing trend of HUA prevalence over time ${ }^{8-10,16}$. It has been reported that the Chinese population of the southeast coastal region have a diet rich in seafood ${ }^{15,17}$. A previous study revealed that consumption of seafood was highly correlated with HUA prevalence ${ }^{18}$. In 
addition, genetic variation may partly explain the high prevalence of HUA among this population.Yang et $a l^{19}$ reported that a high incidence rate of HUA was significantly associated with variants in ABCG2rs2231142 in the Chinese population of the southeast coastal region. Our study also demonstrated that both SUA levels and HUA prevalence were higher in urban areas than in rural areas and in men than in women, which were in line with the previous study as reported by Liu et $a l^{14}$. Aging is an important risk factor of HUA. Our findings revealed that both SUA levels and HUA prevalence increased with age in the urban area. However, they appeared to decrease and stay stable after the age of 50 years in the rural area.

In both sexes, SUA levels and HUA prevalence were relatively stable under age 40 in both urban and rural areas. However, after this age, men appeared to show a downward trend while women show an upward trend. Despite the different trends of both SUA levels and HUA prevalence between men and women, it is evident over a 5-year period that men still bear most of the disease burden. In ages younger than 40 years, The prevalence of HUA in men was $6^{-8}$ times more than that in women (6-8:1 ratio) in both urban and rural areas. In ages older than 60 years, the gender ratio narrowed to $1.5-2: 1$.

To the best of our knowledge, this is the first epidemiological investigation of trends of SUA levels and HUA prevalence in the 
214 The strength of our study is that it uses 5 consecutive years of study data

215 with a large sample size, which is more valuable than the cross-sectional

216 study results. Some limitations of our study should be mentioned. First,

217 our study is a retrospective study and thus the results cannot be

218 generalized to the entire population of southeast China. Second, we

219 cannot analyze the prevalence of gout and the effect of dietary habits and

220 lifestyle on SUA levels and HUA prevalence due to the retrospective data.

221 Finally, the effect of drugs on SUA levels and HUA prevalence cannot be

222 analyzed because the possibility that subjects with normal SUA levels

223 may be receiving urate-lowering therapy cannot be ruled out.

\section{Conclusion}

The current study showed that the SUA levels and the prevalence of HUA substantially increased among urban and rural Chinese populations of the southeast coastal region in 2014-2018. Although there is a downward trend in men and an upward trend in women in the SUA levels and the prevalence of HUA over the 5-year period, men still had the greater disease burden. Special attention should be paid, and effective measures should be taken to lower the HUA prevalence for men in this population. 


\section{Declarations}

236 Ethics approval

237 The protocol was approved by the Research Ethics Committee of the First

238 Affiliated Hospital of Shantou University Medical College and Shantou

239 Chaonan Minsheng Hospital. Written informed consent was obtained

240 from each subject or from a parent in subjects under 18 before data

241 extraction.

242 Consent for publication

243 Not applicable.

244 Availability of data and materials

245 All data generated or analyzed during this study are included in this 246 published article.

Competing interests

248 The authors declare that they have no competing interests.

$249 \quad$ Funding

250 This study was supported by the Grant for Key Disciplinary Project of

251 Clinical Medicine under the Guangdong High-level University

252 Development Program, the Special Funds for Innovation Strategy of

253 Science and Education in Guangdong Province (2018-157), and the grant

254 from Medical Science and Technology Research Fund of Shantou City,

255 Guangdong Province, China (181126154017501).

256 Authors' contributions 
Dr. Li-ping Li and Dr. Yong-song Chen designed, organized and

258 supervised the study. Dr. Xu-xin Zhu contributed to running the study,

259 interpreting the data and draft the first manuscript. Dr. Min-hua $\mathrm{Hu}$

260 contributed to running the study and interpreting the data. Dr Chun-na

261 Wu and Dr Pei-xuan Yang participated in data extraction and coordination.

262 Dr. Li-ping Li had access to all the data in the study and took

263 responsibility for the integrity of the data and the accuracy of the data 264 analysis.

\section{Acknowledgements}

266 We would like to appreciate all of the study participants and thank

267 Editage (www.editage.cn) for English language editing.

268 Author details

$269{ }^{1}$ Department of Endocrinology and Metabolism, the First Affiliated

270 Hospital of Shantou University Medical College, Shantou, Guangdong

271 515041, P. R. China. ${ }^{2}$ The Clinical Research Center, the First Affiliated

272 Hospital of Shantou University Medical College, Shantou, Guangdong

273 515041, P. R. China. ${ }^{3}$ Department of Health Care Center, the First

274 Affiliated Hospital of Shantou University Medical College, Shantou,

275 Guangdong 515041, P. R. China. ${ }^{4}$ Department of Health Care Center,

276 Shantou Chaonan Minsheng Hospital, Shantou, Guangdong 515144, P. R.

277 China. ${ }^{5}$ Department of Prevention Center of Injury, Shantou University,

278 Medical College, Shantou, Guangdong 515041, P. R. China. 


\section{References}

280 1. Kuwabara M, Kuwabara R, Hisatome I, Niwa K, Roncal-Jimenez CA, 281 Bjornstad P, Andres-Hernando A, Sato Y, Jensen T, Garcia G, Ohno M, 282 Hill JO, Lanaspa MA, Johnson RJ. "Metabolically Healthy" obesity and 283 hyperuricemia increase risk for hypertension and diabetes: 5-year 284 Japanese Cohort Study. Obesity (Silver Spring). 2017; 25 (11): 1997 $285-2008$.

2. Johnson RJ, Bakris GL, Borghi C, Chonchol MB, Feldman D, Lanaspa

MA, Merriman TR, Moe OW, Mount DB, Sanchez Lozada LG, Stahl E,

288 Weiner DE, Chertow GM. Hyperuricemia, acute and chronic kidney 289 disease, hypertension, and cardiovascular disease: report of a scientific 290 workshop organized by the National Kidney Foundation. Am J Kidney Dis. 2018; 71(6):851-65.

3. Kim SY, Guevara JP, Kim KM, Choi HK, Heitjan DF, Albert DA. Hyperuricemia and coronary heart disease: A systematic review and meta-analysis. Arthritis Care Res. 2010; 62(2):170 -80.

4. Tariq MA, Shamim SA, Rana KF, Saeed A, Malik BH. Serum uric 296 acid-risk factor for acute ischemic stroke and poor outcomes. Cureus. $297 \quad 2019 ; 11(10): \mathrm{e} 6007$.

298 5. Dehghan A, van Hoek M, Sijbrands EJ, Hofman A, Witteman JC. High 299 serum uric acid as a novel risk factor for type 2 diabetes. Diabetes Care. 300 2008; 31(2):361-62. 
6. Lv Q, Meng XF, He FF, Chen S, Su H, Xiong J, Gao P, Tian XJ, Liu JS,

302 Zhu ZH, Huang K, Zhang C. High serum uric acid and increased risk of 303 type 2 diabetes: a systemic review and meta-analysis of prospective 304 cohort studies. PLoS One. 2013; 8 (2): e56864.

7. Wei CY, Sun CC, Wei JC, Tai HC, Sun CA, Chung CF, Chou YC,

Lin PL, Yang T. Association between hyperuricemia and metabolic syndrome:an epidemiological study of a labor force population in Taiwan. Biomed Res Int.2015; 2015:369179.

8. Wallace KL, Riedel AA, Joseph-Ridge N, Wortmann R. Increasing prevalence of gout and hyperuricemia over 10 years among older adults

311 in a managed care population. J Rheumatol. 2004; 31(8):1582-587.

9. Zhu Y, Pandya BJ, Choi HK. Prevalence of gout and hyperuricemia in 313 the US general population: the National Health and Nutrition 314 Examination Survey 2007-2008. Arthritis Rheum. 2011; 63 (10): 3136 $315-141$.

10. Trifiro G, Morabito P, Cavagna L, Ferrajolo C, Pecchioli S, Simonetti

M, Bianchini E, Medea G, Cricelli C, Caputi AP, Mazzaglia G.

318 Epidemiology of gout and hyperuricaemia in Italy during the years 319 2005-2009: a nationwide population-based study. Ann Rheum Dis. 2013; 72(5):694-700.

11. Chuang SY, Lee SC, Hsieh YT, Pan WH.Trends in hyperuricemia and gout prevalence: Nutrition and Health Survey in Taiwan from 1993-1996 
to 2005-2008. Asia Pac J Clin Nutr. 2011; 20(2):301-08.

12. Hakoda M. Recent trends in hyperuricemia and gout in Japan. Japan Med Assoc J. 2012; 55(4):319-23.

13. Chinese Society of Enducrinology, Chinese Medical Association. Guideline for the diagnosis and management of hyperuricemia and gout in China(2019). Chin J Endocrinol Mteab. 2020; 36(1):1-13.
14. Liu R, Han $\mathrm{C}$, Wu
D, Xia X, Gu J, Guan H, Shan Z, Teng W. Prevalence of hyperuricemia and gout in mainland China from 2000 to 2014: A systematic review and Meta-analysis. Biomed Res Int. 2015; 2015:762820.

15. Xie WJ, Lin ZJ, Zhang XL, Zhang YM. A survey on prevalence and risk factors of hyperuricemia in Shantou. J. Clin Nephrol. 2014; 12 (14): $721-25$.

16. Yan SL, Zhao SH, Li CG, Wang YG, Wang P, Wang ZC, Wang F, Chen Y, Wang F, Miao ZM. A five years follow up study on patients with gout and hyperuricemia. Chin J Endocrinol Metab. 2011; 27(7): 548-52.

17. Zhang GH, Su M, Wang DM, Songnian H, Min L, Jinsong L, Hongbin L, Feng Z, Dongping T, Heling Y, Zhicai L, Shiyong L, Quansheng G, Xiaoyun L, Yuxia G. Genetic heterogeneity of oesophageal cancer in high incidence areas of southern and northern China. PLoS One. 2010; 5(3):e9668.

18. Miao ZM, Li CG, Chen Y, Zhao SH, Wang YG, Wang ZC, Chen XY, 
345 Xu F, Wang F, Sun RX, Hu JX, Song W, Yan SL, Wang CY. Dietary and 346 lifestyle changes associated with high prevalence of hyperuricemia and 347 gout in the Shandong coastal cities of Eastern China. J Rheumatol. 2008; $348 \quad 35(9): 1859-864$.

349 19. Yang XR, Xiao YX, Liu KX, Jiao XY, Lin XZ, Wang YN, Zhang QX. 350 Prevalence of hyperuricemia among the Chinese population of the 351 southeast coastal region and association with single nucleotide 352 polymorphisms in urate- anion exchanger genes: SLC22A12, ABCG2 and 353 SLC2A9. Mol Med Rep. 2018; 18(3):3050-058. 


\section{Legends of the figures}

368

369

370

371

372

373

374

375

376

377

378

379

380

381

382

383

384

385

386

387

388

Figure 1: The SUA levels from 2014 to 2018 were $382.54 \pm 91.17 \mu \mathrm{mol} / \mathrm{L}$, $391.09 \pm 103.80 \mu \mathrm{mol} / \mathrm{L}, 399.92 \pm 102.11 \mu \mathrm{mol} / \mathrm{L}, 405.05 \pm 105.05 \mu \mathrm{mol} / \mathrm{L}$ and $407.38 \pm 103.97 \mu \mathrm{mol} / \mathrm{L}$, respectively in urban areas and $367.75 \pm 90.76 \mu \mathrm{mol} / \mathrm{L}, 382.40 \pm 94.62 \mu \mathrm{mol} / \mathrm{L}, 376.07 \pm 96.59 \mu \mathrm{mol} / \mathrm{L}$, $399.28 \pm 100.41 \mu \mathrm{mol} / \mathrm{L}$ and $398.42 \pm 104.61 \mu \mathrm{mol} / \mathrm{L}$, respectively in rural areas. An increasing trend of SUA levels was observed in both areas $(F=318.211, P<0.01$ in urban areas and $F=150.584, P<0.01$ in rural areas).

Figure 2: The HUA prevalence from 2014 to 2018 was $32.87 \%, 36.58 \%$, $39.78 \%, 41.15 \%$ and $42.41 \%$, respectively in urban areas and $27.81 \%$, $32.29 \%, 30.30 \%, 39.43 \%$ and $38.81 \%$, respectively in rural areas. An increasing trend of HUA prevalence was observed in both areas $(Z=$ 737.894, $P<0.01$ in urban areas and $Z=279.3, P<0.01$ in rural areas).

Figure 3: The SUA levels by the age groups of $<30,30-39,40-49$, $50-59,60-69$ and $\geq 70$ were $389.47 \pm 108.20 \mu \mathrm{mol} / \mathrm{L}, 394.51 \pm 109.62$ $\mu \mathrm{mol} / \mathrm{L}, 394.11 \pm 104.16 \mu \mathrm{mol} / \mathrm{L}, 399.90 \pm 95.01 \mu \mathrm{mol} / \mathrm{L}, 408.21 \pm 96.00$ $\mu \mathrm{mol} / \mathrm{L}$ and $410.75 \pm 99.87 \mu \mathrm{mol} / \mathrm{L}$, respectively in urban areas and $374.83 \pm 104.15 \mu \mathrm{mol} / \mathrm{L}, 393.34 \pm 105.40 \mu \mathrm{mol} / \mathrm{L}, 392.97 \pm 99.54$ $\mu \mathrm{mol} / \mathrm{L}, 388.15 \pm 91.91 \mu \mathrm{mol} / \mathrm{L}, 388.98 \pm 92.18 \mu \mathrm{mol} / \mathrm{L}$ and $389.23 \pm$ 93.72 $\mu \mathrm{mol} / \mathrm{L}$, respectively in rural areas. An increasing trend of SUA levels with age was observed in urban subjects $(F=136.622, P<0.01)$. 
Figure 4: The HUA prevalence by the age groups of $<30,30-39,40-49$, $50-59,60-69$ and $\geq 70$ was $35.94 \%, 38.30 \%, 37.74 \%, 39.04 \%, 41.78 \%$ and $43.04 \%$, respectively in urban areas and $29.92 \%, 38.05 \%, 37.55 \%$, $34.21 \%, 33.72 \%$ and $34.64 \%$, respectively in rural areas. An increasing trend of HUA prevalence with age was observed in urban subjects $(Z$ $=247.659, P<0.01)$.

Figure 5: The SUA levels by the age groups of $<30,30-39,40-49$, $50-59,60-69$ and $\geq 70$ in males were $449.65 \pm 96.68 \mu \mathrm{mol} / \mathrm{L}, 451.39 \pm$ $96.74 \mu \mathrm{mol} / \mathrm{L}, 446.97 \pm 92.34 \mu \mathrm{mol} / \mathrm{L}, 435.99 \pm 90.05 \mu \mathrm{mol} / \mathrm{L}, 430.14 \pm$ $92.95 \mu \mathrm{mol} / \mathrm{L}$ and $426.86 \pm 97.75 \mu \mathrm{mol} / \mathrm{L}$, respectively in urban areas and $437.99 \pm 95.08 \mu \mathrm{mol} / \mathrm{L}, 434.26 \pm 92.80 \mu \mathrm{mol} / \mathrm{L}, 420.60 \pm 88.67 \mu \mathrm{mol} / \mathrm{L}$ $410.42 \pm 86.47 \mu \mathrm{mol} / \mathrm{L}, 404.07 \pm 89.44 \mu \mathrm{mol} / \mathrm{Land} 404.50 \pm 89.61$ $\mu \mathrm{mol} / \mathrm{L}$, respectively in rural areas. A downward trend of SUA levels after age 40 was observed in males in both areas $(F=158.744, P<0.001$ in urban areas and $F=106.403, P<0.001$ in rural areas). The SUA levels in females were $320.57 \pm 74.28 \mu \mathrm{mol} / \mathrm{L}, 320.69 \pm 76.27 \mu \mathrm{mol} / \mathrm{L}, 326.08 \pm$ $74.93 \mu \mathrm{mol} / \mathrm{L}, 360.78 \pm 84.13 \mu \mathrm{mol} / \mathrm{L}, 380.15 \pm 92.46 \mu \mathrm{mol} / \mathrm{L}$ and 380.80 $\pm 96.84 \mu \mathrm{mol} / \mathrm{L}$, respectively in urban areas and $312.11 \pm 68.90 \mu \mathrm{mol} / \mathrm{L}$, $308.60 \pm 71.38 \mu \mathrm{mol} / \mathrm{L}, 314.38 \pm 73.82 \mu \mathrm{mol} / \mathrm{L}, 342.92 \pm 81.97 \mu \mathrm{mol} / \mathrm{L}$ $360.78 \pm 88.10 \mu \mathrm{mol} / \mathrm{L}$ and $360.07 \pm 94.57 \mu \mathrm{mol} / \mathrm{L}$, respectively in rural areas. An upward trend of SUA levels after age 40 was observed in females in both areas $(F=1274.720, P<0.001$ in urban areas and $F=$ 
$411 \quad 188.114, P<0.001$ in rural areas).

412 Figure 6: The HUA prevalence by the age groups of $<30,30-39,40-49$, $41350-59,60-69$ and $\geq 70$ in males was $59.27 \%, 60.20 \%, 59.13 \%, 54.88 \%$, $41451.77 \%$ and $49.92 \%$, respectively in urban areas and $53.43 \%, 53.02 \%$, $41549.79 \%, 42.97 \%, 39.39 \%$ and $40.84 \%$, respectively in rual areas. A 416 downward trend of HUA prevalence after age 40 was observed in males 417 in both areas $(Z=388.510, P<0.001$ in urban areas and $Z=266.700, P<$ 4180.001 in rural areas). The HUA prevalence in females was $9.24 \%, 9.88 \%$, $41910.22 \%, 21.87 \%, 29.00 \%$ and $30.24 \%$, respectively in urban areas and $420 \quad 6.58 \%, 6.38 \%, 8.43 \%, 15.63 \%, 22.32 \%$ and $22.88 \%$, respectively in rural $421 \operatorname{areas}(Z=2826.168, P<0.001$ in urban areas and $Z=444.955, P<0.001$ 422 in rural areas). 


\section{Figures}

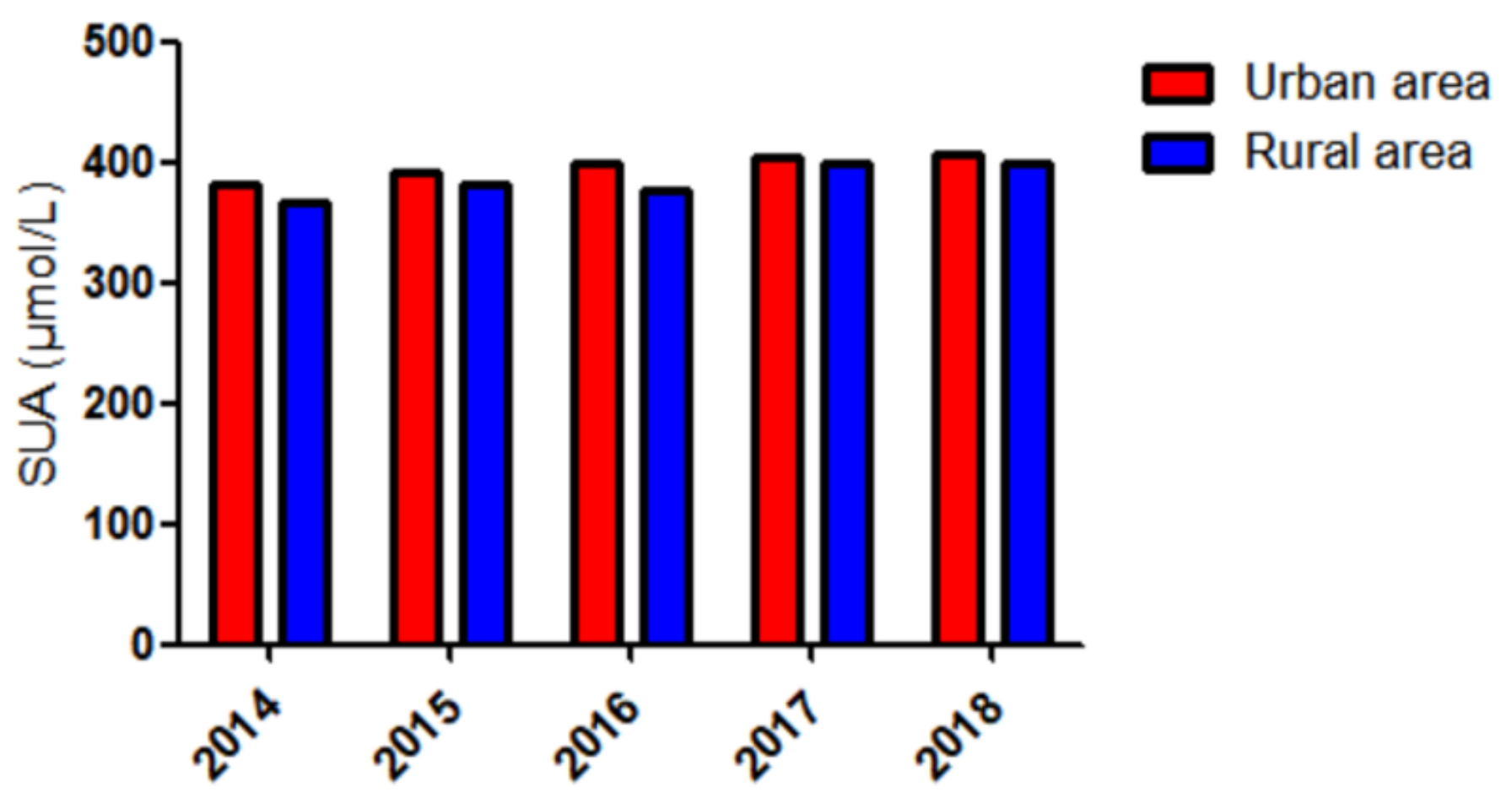

Figure 1

The SUA levels from 2014 to 2018 were $382.54 \pm 91.17 \mu \mathrm{mol} / \mathrm{L}, 391.09 \pm 103.80 \mu \mathrm{mol} / \mathrm{L}, 399.92 \pm 102.11$ $\mu \mathrm{mol} / \mathrm{L}, 405.05 \pm 105.05 \mu \mathrm{mol} / \mathrm{L}$ and $407.38 \pm 103.97 \mu \mathrm{mol} / \mathrm{L}$, respectively in urban areas and $367.75 \pm 90.76 \mu \mathrm{mol} / \mathrm{L}, 382.40 \pm 94.62 \mu \mathrm{mol} / \mathrm{L}, 376.07 \pm 96.59 \mu \mathrm{mol} / \mathrm{L}, 399.28 \pm 100.41 \mu \mathrm{mol} / \mathrm{L}$ and $398.42 \pm 104.61 \mu \mathrm{mol} / \mathrm{L}$, respectively in rural areas. An increasing trend of SUA levels was observed in both areas $(F=318.211, P \llbracket 0.01$ in urban areas and $F=150.584, P \llbracket 0.01$ in rural areas). 


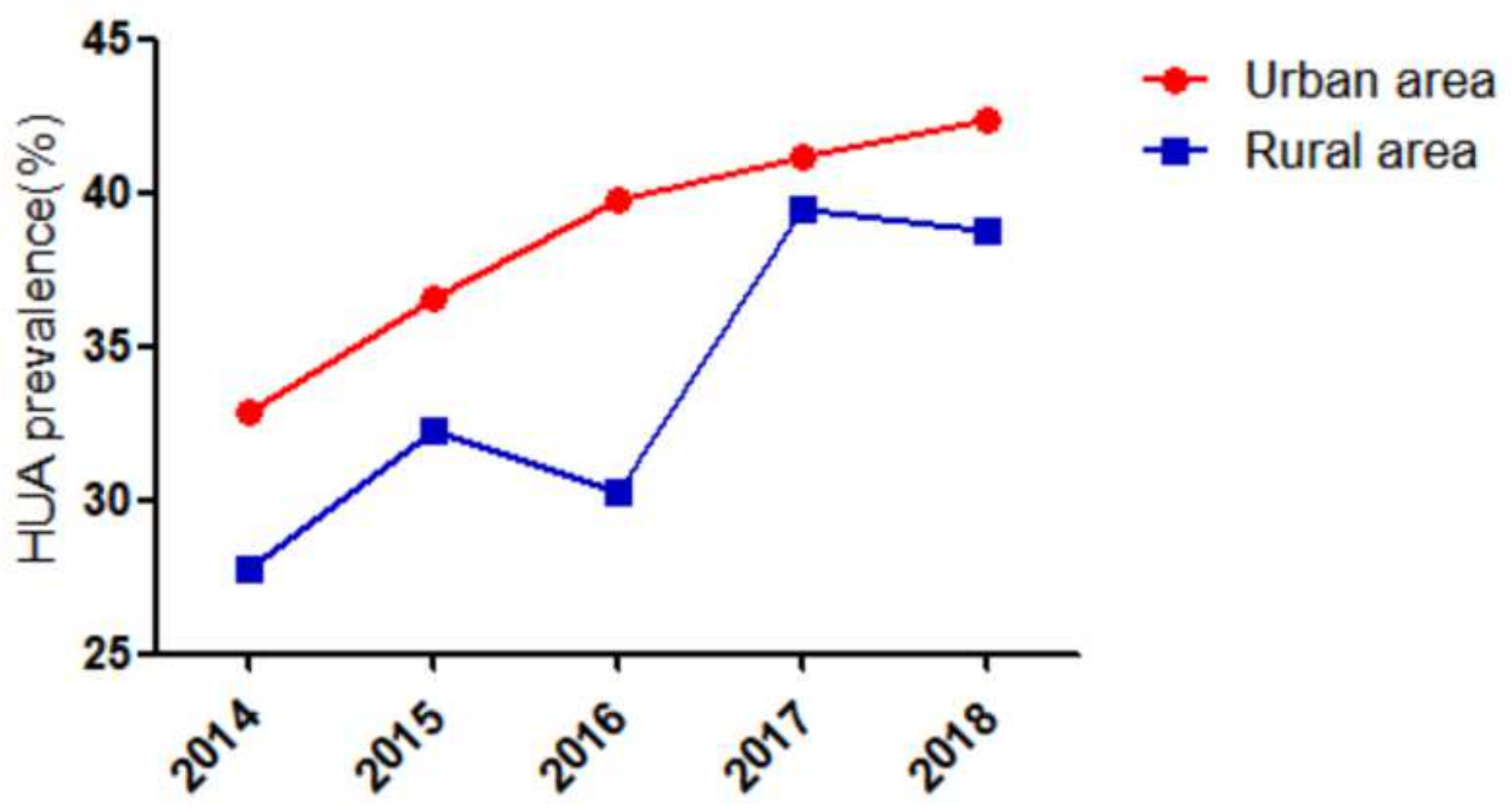

Figure 2

The HUA prevalence from 2014 to 2018 was $32.87 \%, 36.58 \%, 39.78 \%, 41.15 \%$ and $42.41 \%$, respectively in urban areas and $27.81 \%, 32.29 \%, 30.30 \%, 39.43 \%$ and $38.81 \%$, respectively in rural areas. An increasing trend of HUA prevalence was observed in both areas $(Z=737.894, P \llbracket 0.01$ in urban areas and $Z=279.3, P \rrbracket$ 0.01 in rural areas).

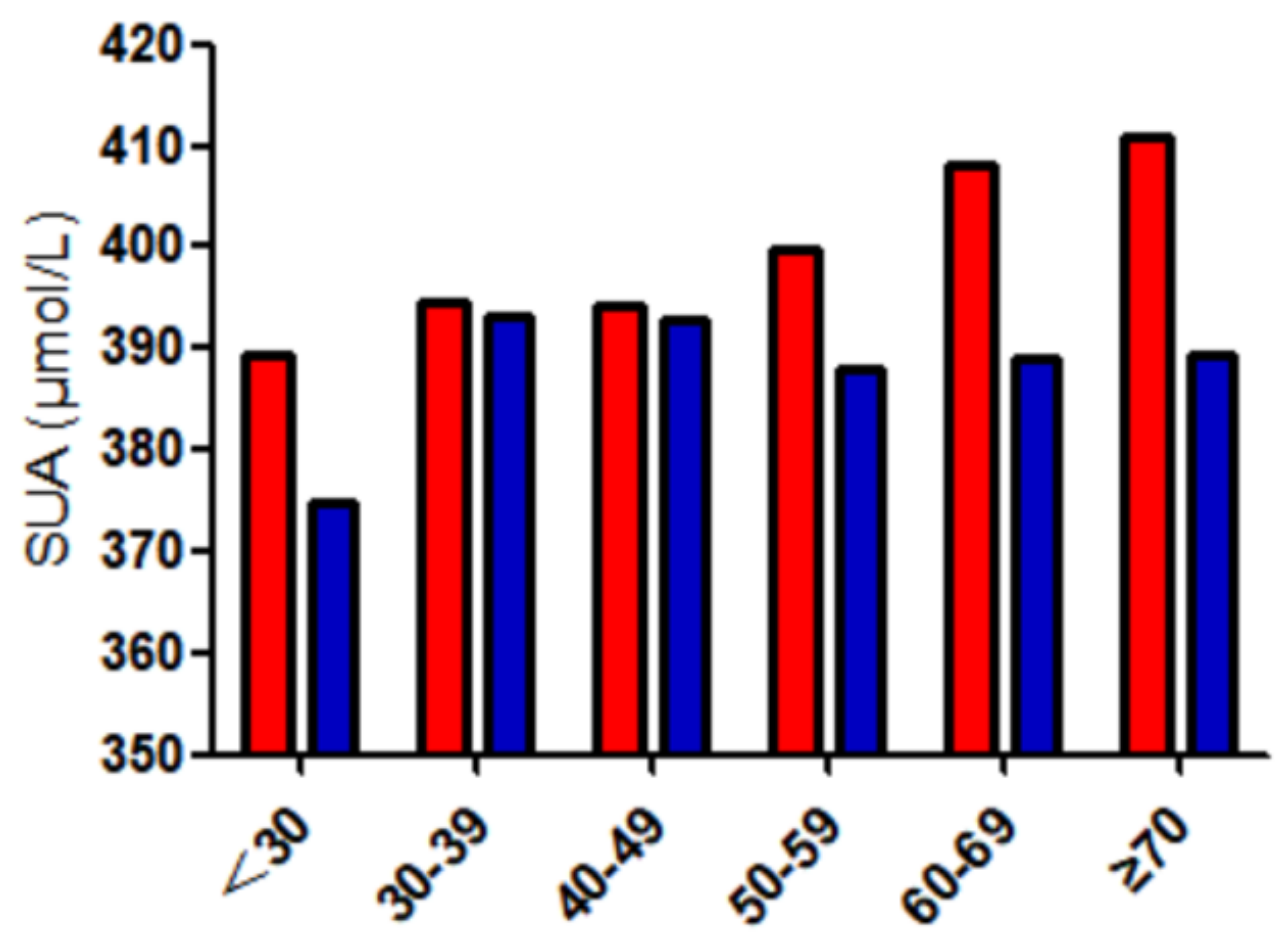

$\square$ Urban area $\square$ Rural area 


\section{Figure 3}

The SUA levels by the age groups of $₫ 30,30-39,40-49,50-59,60-69$ and $\geq 70$ were $389.47 \pm 108.20 \mu \mathrm{mol} / \mathrm{L}$, $394.51 \pm 109.62 \mu \mathrm{mol} / \mathrm{L}, 394.11 \pm 104.16 \mu \mathrm{mol} / \mathrm{L}, 399.90 \pm 95.01 \mu \mathrm{mol} / \mathrm{L}, 408.21 \pm 96.00 \mu \mathrm{mol} / \mathrm{L}$ and $410.75 \pm 99.87 \mu \mathrm{mol} / \mathrm{L}$, respectively in urban areas and $374.83 \pm 104.15 \mu \mathrm{mol} / \mathrm{L}, 393.34 \pm 105.40 \mu \mathrm{mol} / \mathrm{L}$, $392.97 \pm 99.54 \mu \mathrm{mol} / \mathrm{L}, 388.15 \pm 91.91 \mu \mathrm{mol} / \mathrm{L}, 388.98 \pm 92.18 \mu \mathrm{mol} / \mathrm{L}$ and $389.23 \pm 93.72 \mu \mathrm{mol} / \mathrm{L}$, respectively in rural areas. An increasing trend of SUA levels with age was observed in urban subjects $(F=136.622, P \bowtie 0.01)$.

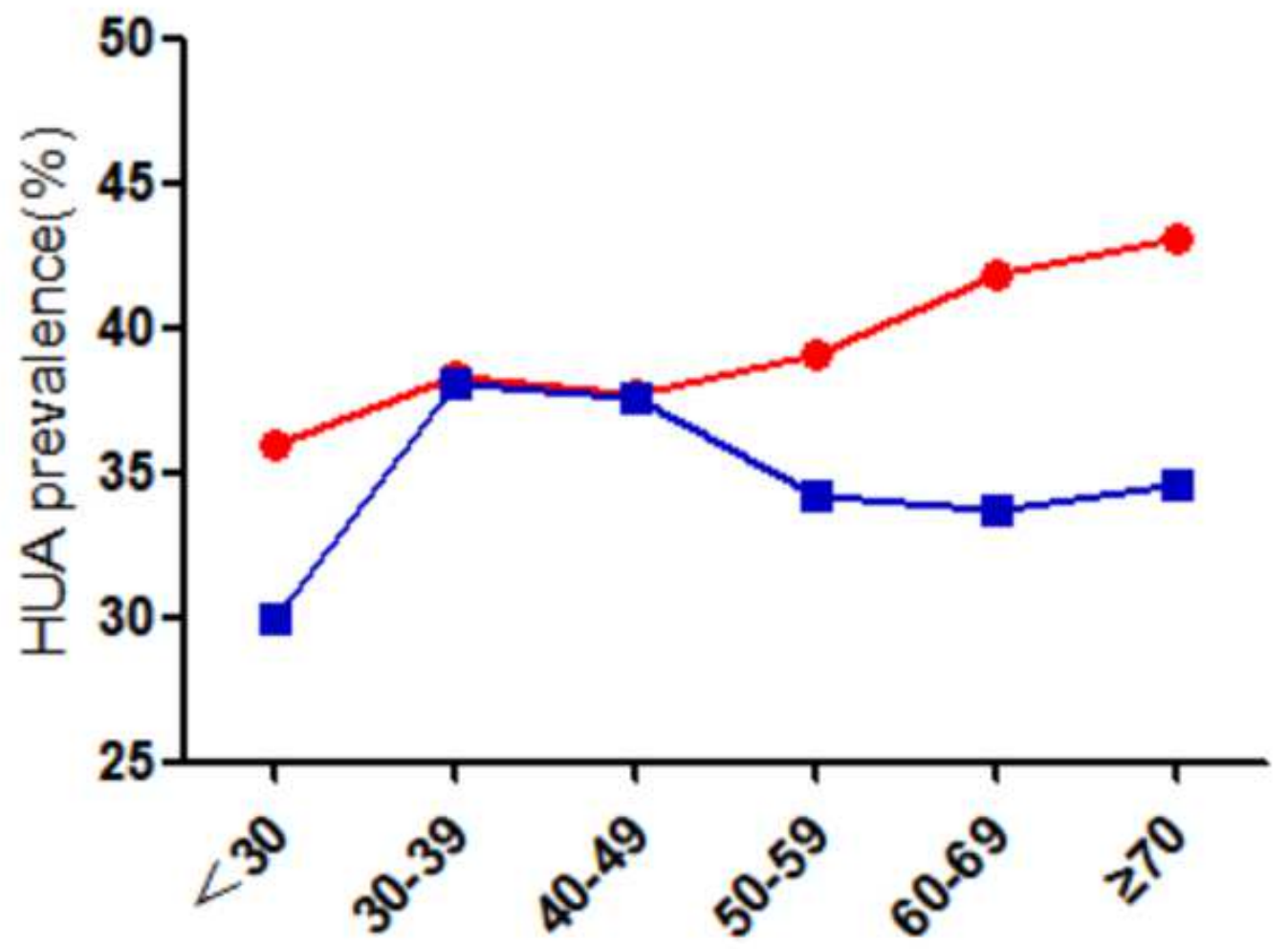

* Urban area - Rural area

Figure 4

The HUA prevalence by the age groups of $₫ 30,30-39,40-49,50-59,60-69$ and $\geq 70$ was $35.94 \%, 38.30 \%$, $37.74 \%, 39.04 \%, 41.78 \%$ and $43.04 \%$, respectively in urban areas and $29.92 \%, 38.05 \%, 37.55 \%, 34.21 \%$, $33.72 \%$ and $34.64 \%$, respectively in rural areas. An increasing trend of HUA prevalence with age was observed in urban subjects $(Z=247.659, \mathrm{P} \otimes 0.01)$. 


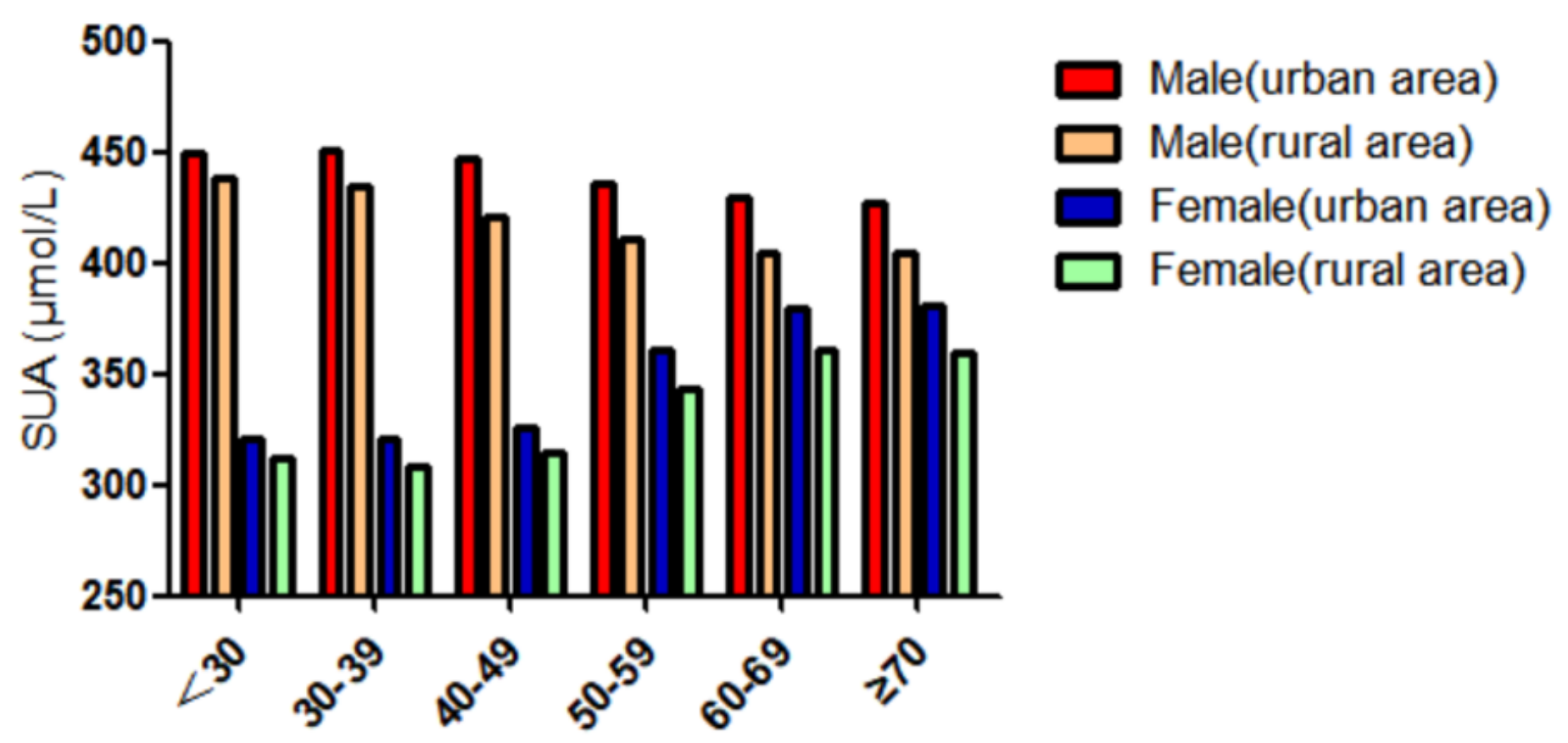

Figure 5

The SUA levels by the age groups of $₫ 30,30-39,40-49,50-59,60-69$ and $\geq 70$ in males were $449.65 \pm 96.68$ $\mu \mathrm{mol} / \mathrm{L}, 451.39 \pm 96.74 \mu \mathrm{mol} / \mathrm{L}, 446.97 \pm 92.34 \mu \mathrm{mol} / \mathrm{L}, 435.99 \pm 90.05 \mu \mathrm{mol} / \mathrm{L}, 430.14 \pm 92.95 \mu \mathrm{mol} / \mathrm{L}$ and $426.86 \pm 97.75 \mu \mathrm{mol} / \mathrm{L}$, respectively in urban areas and $437.99 \pm 95.08 \mu \mathrm{mol} / \mathrm{L}, 434.26 \pm 92.80 \mu \mathrm{mol} / \mathrm{L}$, $420.60 \pm 88.67 \mu \mathrm{mol} / \mathrm{L}, 410.42 \pm 86.47 \mu \mathrm{mol} / \mathrm{L}, 404.07 \pm 89.44 \mu \mathrm{mol} / \mathrm{L}$ and $404.50 \pm 89.61 \mu \mathrm{mol} / \mathrm{L}$, respectively in rural areas. A downward trend of SUA levels after age 40 was observed in males in both areas $(F=158.744, P \llbracket 0.001$ in urban areas and $F=106.403, P \llbracket 0.001$ in rural areas). The SUA levels in females were $320.57 \pm 74.28 \mu \mathrm{mol} / \mathrm{L}, 320.69 \pm 76.27 \mu \mathrm{mol} / \mathrm{L}, 326.08 \pm 74.93 \mu \mathrm{mol} / \mathrm{L}, 360.78 \pm 84.13 \mu \mathrm{mol} / \mathrm{L}$, $380.15 \pm 92.46 \mu \mathrm{mol} / \mathrm{L}$ and $380.80 \pm 96.84 \mu \mathrm{mol} / \mathrm{L}$, respectively in urban areas and $312.11 \pm 68.90 \mu \mathrm{mol} / \mathrm{L}$, $308.60 \pm 71.38 \mu \mathrm{mol} / \mathrm{L}, 314.38 \pm 73.82 \mu \mathrm{mol} / \mathrm{L}, 342.92 \pm 81.97 \mu \mathrm{mol} / \mathrm{L}, 360.78 \pm 88.10 \mu \mathrm{mol} / \mathrm{L}$ and $360.07 \pm 94.57 \mu \mathrm{mol} / \mathrm{L}$, respectively in rural areas. An upward trend of SUA levels after age 40 was observed in females in both areas $(F=1274.720, P \otimes 0.001$ in urban areas and $F=188.114, P \llbracket 0.001$ in rural areas). 


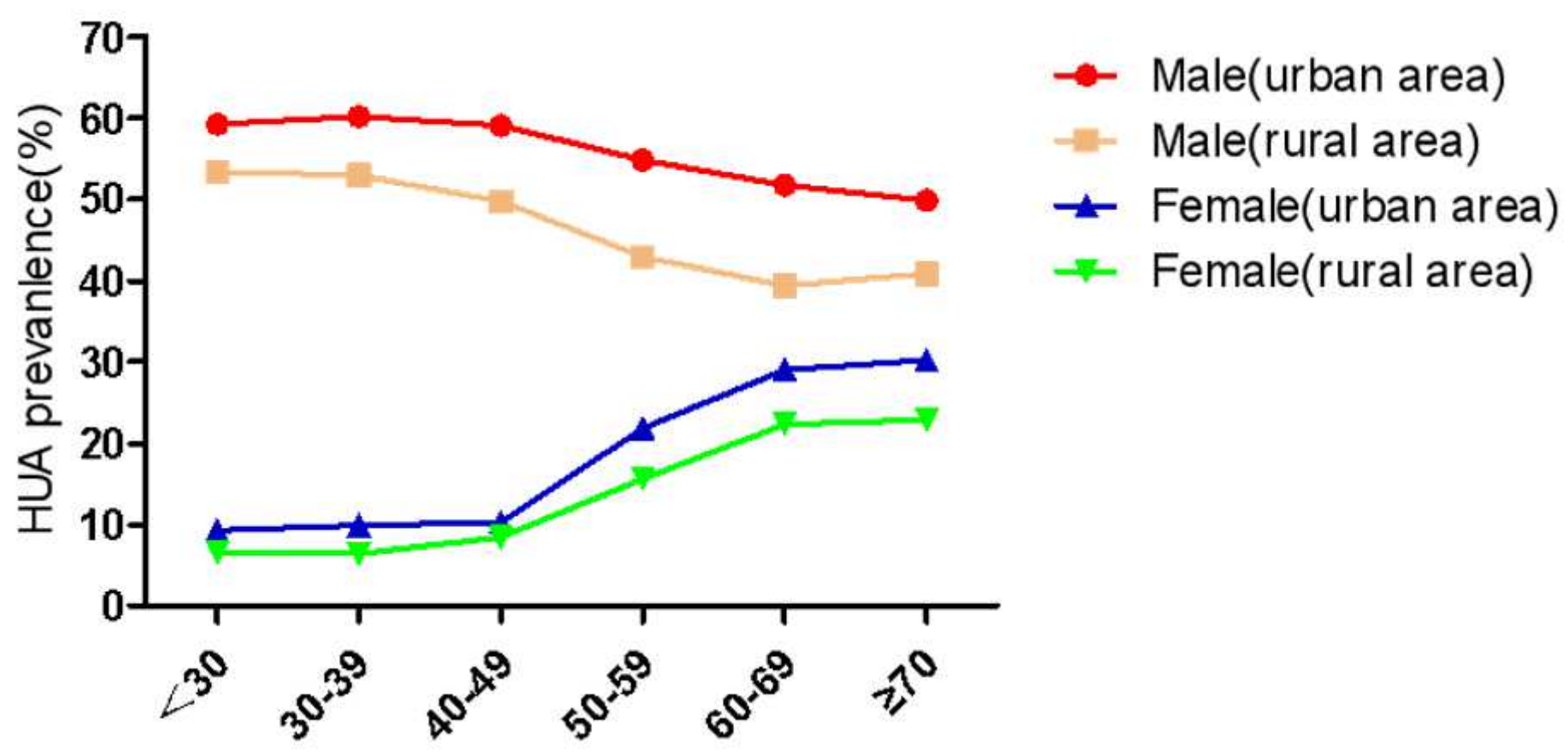

Figure 6

The HUA prevalence by the age groups of $₫ 30,30-39,40-49,50-59,60-69$ and $\geq 70$ in males was $59.27 \%$, $60.20 \%, 59.13 \%, 54.88 \%, 51.77 \%$ and $49.92 \%$, respectively in urban areas and $53.43 \%, 53.02 \%, 49.79 \%$, $42.97 \%, 39.39 \%$ and $40.84 \%$, respectively in rual areas. A downward trend of HUA prevalence after age 40 was observed in males in both areas $(Z=388.510, P \otimes 0.001$ in urban areas and $Z=266.700, P \bowtie 0.001$ in rural areas). The HUA prevalence in females was $9.24 \%, 9.88 \%, 10.22 \%, 21.87 \%, 29.00 \%$ and $30.24 \%$, respectively in urban areas and $6.58 \%, 6.38 \%, 8.43 \%, 15.63 \%, 22.32 \%$ and $22.88 \%$, respectively in rural $\operatorname{areas}(Z=2826.168, P \otimes 0.001$ in urban areas and $Z=444.955, P \Downarrow 0.001$ in rural areas). 